\title{
Projetando o espectro do som no espaço: imagens-movimento de parciais e grãos sonoros
}

Danilo Rossetti ${ }^{1}$

Universidade Federal do Mato Grosso d.a.a.rossetti@gmail.com 


\section{Resumo}

Enquanto o tempo é sempre mencionado como característica inerente à música, o espaço na maioria das vezes não é tratado como categoria operatória da composição, algo que mudou de figura durante o século XX devido a novas abordagens composicionais e teóricas. Este artigo apresenta a construção de um instrumento digital em Max/MSP maleável a diferentes configurações de difusão sonora e congregando diferentes possibilidades de síntese com espacialização em ambissonia de ordem superior, com o intuito de integrar o espectro do som à espacialização na música eletroacústica (acusmática ou mista) pela projeção de parciais e/ou grãos em movimento no espaço de difusão. Para tanto, são apresentados os seguintes referenciais teóricos: 1) abordagens históricas do espaço na composição musical com ênfase nos séculos $X X$ e $X X I$; 2) o sistema Ambisonics; e 3) uma conceituação sobre os modelos sonoros ondulatório e granular, dessa forma situando a proposta na área da criação musical para sistemas com grande densidade de alto-falantes. Como resultados, apresento as ferramentas de composição e espacialização incluídas no instrumento digital desenvolvido, além do experimento composicional Imagens transdutivas. Como conclusão, esboça-se uma reflexão sobre a percepção sonora em sistemas imersivos a partir das ideias de imagem-movimento e blocos de espaço-tempo.

Palavras-chave: Música eletroacústica; espaço; morfologia sonora; ambissonia de ordem superior; sistemas imersivos..

\section{Abstract}

While time is always mentioned as an inherent feature of music, space in most of the times is not included as an operatory feature in composition, something that has changed during the 20th Century due to new compositional and theoretical approaches. This article addresses the construction of a digital instrument in Max/MSP malleable to different conditions of sound diffusion and gathering different possibilities of sound synthesis and high-order ambisonics spatialization, searching to integrate the sound spectrum to the spatialization in electroacoustic music (acousmatic or live-electronics) from the projection of partials and/or grains in movement in the diffusion space. In this context, we present the following theoretical background: 1) historical approaches of space in musical composition, mainly in 20th and 21st Centuries; 2) the ambisonics system, and 3) a conceptualization on the undulatory and granular sound models, situating our proposal in the field of musical composition for high density loudspeaker arrays. As a result, I discuss the composition and spatialization tools included in the digital instrument developed, besides the compositional experiment Imagens transdutivas. As a conclusion, we outline some considerations on sound perception in immersive systems from the ideas of movement image and blocks of space-time.

Keywords: Electroacoustic music; space; sound morphology; high-order ambisonics; immersive systems. 


\section{O tempo do som e a representação do espectro sonoro}

Quando se discutem as propriedades intrínsecas da música quanto às suas características acústicas e perceptivas, afirma-se, dentre outras coisas, que ela é uma arte temporal (ROSSETTI, 2010). Dificilmente podemos refutar tal afirmação, pois certamente precisamos do elemento do tempo tanto para escutar quanto para tocar ou para compor alguma música. O tempo torna possível que a música se desenvolva, que entendamos o desenrolar de suas ideias, frases, melodias, percursos e, consequentemente, que percebamos a sua forma. Sem o tempo, não há música, ao menos a música experienciada de maneira factual ${ }^{2}$.

Assim, no momento da sua realização temporal (ou execução musical), o caráter frequencial da música, ou seja, o seu espectro, é revelado. Utilizo o termo "frequencial" porque me refiro principalmente ao som do ponto de vista acústico e/ou perceptivo, à sua decomposição em diferentes partes (ou parciais), suas manipulações e operações, e, em menor nível, à relação desses componentes com alturas musicais, escalas ou acordes. Ressalto que também será abordada, mais adiante, a possibilidade da composição do som pela junção (justaposição e sobreposição) de inúmeros grãos sonoros.

O espectro sonoro é uma representação de um som no tempo, tendo em vista a sua decomposição em diferentes parciais e suas respectivas intensidades (SETHARES, 2005, p.13-27). A partir de representações desse tipo, pode-se ter acesso ao universo interno do som e conhecer o tipo de material que pertence ao seu conteúdo. Com essa possibilidade, passou-se a manipular amostras sonoras de durações muito pequenas, em escalas inferiores à notação da partitura musical tradicional, medidas em milissegundos. Esse universo que se situa abaixo do limite inferior das durações das figuras da notação musical possui diferentes denominações, tais como microfônico (GRISEY, 1979) ou microtempo (ROADS, 2002).

A partir da segunda metade do século XX, com o advento de ferramentas tecnológicas que possibilitavam a análise do espectro sonoro, alguns compositores passaram a utilizar essas informações em seus processos composicionais de diferentes formas. Dentre os exemplos importantes, mencionamos os processos de manipulação espectral utilizados por compositores de música eletrônica do Estúdio de Colônia, especialmente os utilizados por Karlheinz Stockhausen em suas peças Studie II (1954) e Gesang der Jünglinge (1955-1956), assim como o trabalho dos compositores da corrente espectral francesa, tais como Jean-Claude Risset, Gérard Grisey e Tristan Murail, que realizavam operações a partir de dados extraídos de espectros sonoros utilizados na poética de suas composições. Nesse contexto, citamos como exemplos as peças Mutations I (1969) e Mutations II (1973), de Risset, Partiels (1975), de Grisey, e Treize couleurs du soleil couchant (1978), de Murail.

2 Aqui não há referência às abstrações musicais, à música teórica ou à harmonia concebida pelos gregos antigos (Pitágoras, Platão, Aristóteles) e teóricos musicais da Idade Média e Renascimento (Kepler, Zarlino, Kircher), as quais poderiam existir fora do tempo (XENAKIS, 1965, 1967). Estas não têm a necessidade de sua realização prática em forma de som, pois tratavam principalmente de especulações, cálculos, proporções e abstrações, com um objetivo filosófico ou estético. 


\section{O espaço como categoria da composição musical}

Além das características temporais da música, um dos intuitos deste texto é ressaltar a ideia do espaço como categoria operatória da composição musical, através de uma possível composição do som integrada ao espaço físico ${ }^{3}$ (SOLOMOS, 2013, p.415-425). No período renascentista, o espaço teria sido uma importante categoria composicional, cuja exploração é, de certa forma, intermitente. Nesse período, temos, por exemplo, a criação do célebre moteto religioso Spem in Alium (1556-1570), de Thomas Tallis, para oito coros de cinco vozes cada, distribuídos no espaço da performance. Outro exemplo importante, já no século XIX, é o "Tuba Mirum" do Requiem (1837), de Hector Berlioz, em que quatro pequenas orquestras de instrumentos de metal devem ser dispostas isoladamente, nos quatro ângulos da grande massa instrumental e coral (SOLOMOS, 2013, p.420).

Durante o século $X X$, com o surgimento da música eletroacústica, o espaço pode ser retrabalhado como categoria composicional estruturante, devido à disposição dos alto-falantes preenchendo o local das salas de concerto, permitindo o pensamento de uma espacialização do som. Gesang der Jünglinge foi a primeira obra a ter essa concepção, com uma espacialização concebida inicialmente para cinco canais e, posteriormente, reduzida para quatro canais. Outro exemplo dos anos 1950 é o Pavilhão Philips, em que "rotas de som" foram criadas no espaço interno do edifício, para a difusão das obras Poème électronique, de Edgar Varèse, e Concret $\mathrm{PH}$, de lannis Xenakis, ambas de 1958, sonorizadas por cerca de 400 alto-falantes. Os Polytopes de Xenakis (KANACH, 2008, p.198-277) são outras importantes realizações musicais que integram o espaço como categoria composicional por meio da ideia de imersão sonora e visual. Há também exemplos de peças instrumentais para grandes formações em que a disposição dos músicos é feita de maneira não convencional. Nessa categoria se encaixam peças como Gruppen (1955-1957), de Stockhausen, para três orquestras, e Terretektorth (1965-1966), de Xenakis, para 88 músicos espalhados pela sala de concerto, ao redor do público.

Alguns importantes textos mencionam diferentes maneiras de integrar o espaço como variável composicional. Em "Musik im Raum" (1958), Stockhausen descreveu alguns procedimentos que integram o espaço a outras categorias composicionais (alturas, intensidades, timbres, durações) utilizadas em suas obras compostas nesse período. Em "Tempo e espacialidade: em busca dos lugares do tempo" (1993), Emmanuel Nunes propôs uma relação entre a concepção do espaço virtual de difusão na música mista e o tempo da notação rítmica instrumental. Essa ideia foi extensivamente desenvolvida na composição de seu ciclo de obras Lichtung I, II e III, entre 1988 e 2007, nas quais a rítmica instrumental, em conjunto com processamentos sonoros, é projetada em tempo real no espaço por meio dos movimentos e gestos sonoros ao longo da performance. No caso da concepção de Nunes, observamos uma poética que buscava interligar a escrita

3 Muitas vezes se utiliza o termo "espaço" para se abordar as frequências ou alturas utilizadas numa obra musical, especialmente quando nos situamos dentro da estética da música serial, seja ela dodecafônica ou pertencente ao serialismo integral (SCHOENBERG, 1941; BOULEZ, 1963). Porém, não é esse o espaço composicional que será abordado. 
do tempo musical da partitura com uma escrita da espacialização sonora, por meio de uma relação entre o ritmo e os pontos de espacialização.

A proposta que procurarei desenvolver neste texto, relacionada aos exemplos teóricos mencionados acima, é uma possível integração, em uma operação única, do processamento do espectro sonoro e da espacialização, para ser utilizada em processos criativos ligados à música eletroacústica acusmática ou mista. Para tanto, foram criadas algumas ferramentas computacionais em Max/MSP que buscam integrar processamentos sonoros, tais como modulação em anel, granulação, delay e síntese FM com uma espacialização sonora realizada em ambissonia de ordem superior (DANIEL; NICOL; MOREAU, 2003). É importante ressaltar que essa ideia já teve realizações anteriores através de ferramentas que relacionavam esses aspectos de processamento sonoro e especialização (WAKEFIELD, 2006; SĖDES; GUILLOT; PARIS, 2014). Este último trabalho aborda o projeto da biblioteca externa $\mathrm{HOA}^{4}$ (High-Order Ambisonics) para Max/MSP e Pure Data, que esteve ativo entre 2012 e $2015^{5}$.

Em um artigo de 2018 (ROSSETTI, 2018) apresentei algumas ferramentas de análise e processamento sonoro ligadas a processamentos espectrais e granulares. A diferença das ferramentas abordadas neste presente artigo das desenvolvidas anteriormente, além das citadas no parágrafo anterior, é o fato de que este último trabalho visa contribuir para o campo da criação musical multicanal, área que vem se desenvolvendo intensamente nos últimos anos, com a criação de espaços experimentais de difusão sonora com uma grande densidade de alto-falantes, conhecidos como high-density loudspeaker arrays. Nesse contexto, mencionamos alguns trabalhos, como o de Torchia e Lippe (2004), que descrevem técnicas para uma distribuição espacial usando processamentos frequenciais; de Normandeau (2009), que aborda processos de espacialização do timbre; de Garavaglia (2016), que narra um experimento de espacialização multicanal atrelado à síntese granular; e de Lyon (2019), que discute uma coleção de técnicas de desenho sonoro multicanal (multichannel sound design). Ademais, em termos conceituais, existem ressonâncias com artigos precedentes de Menezes (1999) e Barreiro (2017).

\section{Ambisonics}

Aqui apresento uma breve abordagem histórica dos sistemas de ambissonia e suas transformações ao longo do tempo, já que essa tecnologia é empregada nas ferramentas de criação sonora que discutirei neste artigo. Enfatizo nesta rápida apresentação principalmente as questões operacionais do sistema e suas funcionalidades para a reconstrução de campos sonoros imersivos, porém não entrando em questões demasiadamente técnicas de seu funcionamento.

\footnotetext{
$4 \quad$ Tive contato direto com os desenvolvedores dessa biblioteca em meu estágio de doutorado na Universidade Paris 8 e a utilizei em diversas composições mistas.

5 A partir de 2019, esse projeto se voltou para a espacialização do som e imersão sonora em ambientes de realidade virtual desenvolvidos no programa Unity. Mais detalhes estão disponíveis em: http://hoalibrary.mshparisnord.fr.
} 
O Ambisonics (ou ambissonia) é um sistema de espacialização sonora que busca reconstruir um campo único imersivo, a fim de que os alto-falantes não sejam audíveis como fontes sonoras separadas (FELLGETT, 1975). Nesse sentido, em sistemas de ambissonia, cada alto-falante (ao menos três) emite uma onda com determinada amplitude e fase com o intuito de simular a audição presencial de um indivíduo no local onde a gravação original foi realizada. Para tanto, durante a captação do som, um processo de codificação do campo sonoro para esse sistema (inicialmente de primeira ordem) é realizado. No momento da reprodução da gravação em um sistema multicanal, por sua vez, é realizado o processo de decodificação do sistema de ambissonia para a difusão sonora, de acordo com quantidade de alto-falantes estipulada (GERZON, 1975).

Nos anos 2000, melhorias consideráveis nesses sistemas foram realizadas, como a sua expansão para resoluções espaciais, que propiciaram maior detalhamento e exatidão de localização (DANIEL; NICOL; MOREAU, 2003). Esses sistemas ficaram conhecidos como ambissonia de ordem superior (high-order ambisonics - HOA). Neles, a decodificação espacial do sinal sonoro realiza uma transformada discreta de Fourier aplicada ao domínio dos harmônicos esféricos ${ }^{6}$. Dessa maneira, a HOA apresenta a possibilidade de reconstrução acústica de uma grande área de escuta, área esta conhecida como holofonia, contudo, é necessária uma quantidade maior de alto-falantes para que essa reconstrução seja percebidacom qualidade (DANIEL, 2009).

Em um sistema de ambissonia, os harmônicos são funções utilizadas na decomposição do espaço e representam os sons e suas funções espaciais, sendo elas circulares (em 2D) ou esféricas (em 3D). Essas funções têm como variáveis o azimute, nos harmônicos circulares, e o azimute e a elevação, nos harmônicos esféricos. Os harmônicos, por sua vez, dependem de um grau $l$ e de uma ordem de azimute $m$. Nos harmônicos circulares, cada grau l compreende dois harmônicos, cujas ordens são $m=-l$ e $m=l$ (o grau 0 tem apenas um harmônico de ordem 0). Para os harmônicos esféricos, cada grau l tem 2 l + 1 harmônicos, cujas ordens vão de - l a l. A decomposição de um campo sonoro no domínio dos harmônicos se efetua a partir da ordem de decomposição $N$, que compreende todos os graus de 0 a $N$. Assim, em 2D, o campo sonoro é composto de $2 N+1$ harmônicos circulares, e, em 3D, o campo sonoro é composto de $(N+1)^{2}$ harmônicos esféricos (COLAFRANCESCO; GUILLOT; PARIS, 2015).

A partir da explicação acima, em 2D, por exemplo, para uma ordem de decomposição $\mathrm{N}=3$, há 7 harmônicos, considerando seus graus e ordens, sendo eles (grau, ordem): $(0,0),(1,-1),(1,1),(2,-2),(2,2),(3,-3)$ e $(3,3)$, além de uma necessidade mínima de 7 alto-falantes na difusão sonora. Em 3D, para uma ordem de decomposição $\mathrm{N}=3$, há 16 harmônicos, sendo eles $(0,0),(1,-1),(1,0),(1,1),(2,-2),(2,-1),(2,0),(2,1),(2,2)$, $(3,-3),(3,-2),(3,-1),(3,0),(3,1),(3,2)$ e $(3,3)$, além de, no mínimo, serem necessários 16 alto-falantes na difusão sonora. Neste artigo apresentarei somente ferramentas implementadas em ambissonia de terceira ordem em 2D.

\footnotetext{
6 A representação do som no espaço por ambissonia de ordem superior se baseia na descrição do campo sonoro a partir de um sistema de coordenadas formado por harmônicos circulares (2D) ou esféricos (3D). Essa representação ocorre a partir de uma operação que decompõe o campo sonoro em uma soma ponderada de funções espaciais, de maneira análoga à decomposição do som em parciais pela transformada de Fourier. A descrição espacial obtida tem a propriedade de realizar uma descrição homogênea da informação direcional (ângulo e elevação) separadamente da informação da distância (raio) (DANIEL, 2003).
} 


\section{Modelos sonoros ondulatório e granular}

Em minha tese de doutorado (ROSSETTI, 2016), abordei diferentes processos de criação sonora baseados em manipulações em escalas microtemporais do som, os quais dividi como pertencentes a duas categorias: o paradigma ondulatório e o paradigma granular. Apresentarei a conceituação desses dois paradigmas e as técnicas de manipulação relacionadas a eles. Essa conceituação será útil para o entendimento das ferramentas composicionais que apresento mais adiante.

\subsection{0 paradigma ondulatório}

O paradigma ondulatório é da ordem do contínuo, em que o espectro sonoro é decomposto em uma soma de parciais, cada qual com suas intensidades e diferenças de fase, formando o som em sua totalidade. A partir dessa maneira de conceber a construção do som, pode-se ter ao menos duas propostas para a percepção das alturas musicais, ambas originárias da psicoacústica do século XIX. Resumidamente, a primeira proposta, de Helmholtz, afirma que a percepção das alturas ocorre a partir de uma espécie de análise espectral (transformada de Fourier) realizada pelo nosso ouvido, na qual o parcial mais grave indica a altura do som percebido. A outra proposta, de Seebeck, propõe a existência de um fenômeno chamado de altura periódica (periodicity pitch), em que, se retirarmos a frequência fundamental de determinado som, continuamos a percebê-lo com a mesma altura. A partir dessa última proposta, chega-se à conclusão de que não é apenas a frequência fundamental que determina a altura de um som, mas também a disposição proporcional de seus parciais superiores (acima do décimo quinto).

Essas duas propostas tiveram seus desdobramentos durante o século XX, como as ideias de altura residual (residual pitch), altura formântica (formant pitch) e altura virtual (virtual pitch), ligadas à segunda proposta, e altura espectral (spectral pitch), ligada à primeira proposta (ROSSETTI, 2016, p.55-61). No Solfejo do objeto sonoro, de Pierre Schaeffer e Guy Reibel (1967), encontramos a exploração, com exemplos sonoros, da proposta da altura periódica ou som residual.

Dentro da concepção do paradigma ondulatório no campo musical, temos também, no período da virada do século XIX para o século XX, a proposta dos acordes-timbre, uma espécie de fusão entre harmonia e timbre, tal como encontramos nas obras para piano de Debussy e Scriabin e, posteriormente, em outros compositores, como Messiaen. Nessas construções, a maneira de organização sucessiva dos acordes sugere que eles sejam apreendidos como sons globais (objetos únicos) ou puros timbres. Outra proposta desse período é a Klangfrabenmelodie (melodia de timbres), que encontramos na música de Schoenberg e Webern, que funciona como um prolongamento espectral da harmonia, similarmente a uma transição gradual e contínua de diferentes timbres e/ ou harmonias (SOLOMOS, 2013, p.66-69; ROSSETTI, 2017).

Com o início da manipulação sintética de sons, de forma analógica ou digital, a partir dos anos 1950, temos uma ampliação considerável das técnicas de construção sonora 
que podemos classificar como ligadas a esse paradigma. Dentre essas técnicas, citamos, entre outras, a síntese aditiva, a síntese por modulação de amplitude (AM) e modulação em anel e a síntese por modulação de frequência (FM). Mais detalhes sobre esses processamentos podem ser encontrados na tese mencionada (ROSSETTI, 2016, p.64-75).

\subsection{0 paradigma granular}

O paradigma granular é da ordem do descontínuo e ganhou destaque, nos anos 1940, por meio da teoria do quanta acústico de Dennis Gabor, uma espécie de proposta teórica do átomo sonoro. Solomos (2013, p.396-397) afirma que o paradigma granular está ligado à descrição corpuscular do som, em oposição à descrição ondulatória na qual a ideia de "grãos" corresponde a amostras sonoras extremamente curtas, pertencentes à escala microtemporal. Construir um som a partir dessas bases consiste em justapor uma imensa quantidade de grãos, manipulando sua densidade global e suas qualidades espectrais. Essa teoria ganhou força na composição musical após a proposta de Xenakis, apresentada na introdução do segundo capítulo de seu livro Musiques formelles (1962), da seguinte maneira:

Todo som seria uma integração de grãos, de partículas sonoras elementares, de quanta sonoros. Cada um desses grãos elementares tem uma natureza tripla: duração, frequência e intensidade. Todo som, toda variação sonora, mesmo contínua, é concebida como um agrupamento de grãos elementares suficientemente numerosos e dispostos no tempo de uma maneira adequada. (XENAKIS, 1962, p.61, tradução nossa) ${ }^{7}$.

Em uma demonstração da aplicação prática do paradigma granular na composição,Xenakis, no mesmo capítulo de Musiques formelles, apresenta uma análise de sua obra Analogique A \& B (1958-1959), para orquestra de cordas e sons fixados em suporte (tape). Outra peça dele do mesmo período, composta em moldes similares, é Concret $\mathrm{PH}$. Ligada à musique concrète, Concret $\mathrm{PH}$ foi realizada no GRM de Paris e sua sonoridade granular é atingida por procedimentos de edição de fita no estúdio, tal como uma espécie de síntese granular realizada em meios analógicos.

Além dos procedimentos composicionais de Concret $P H$, podemos ter outras técnicas digitais ligadas a esse paradigma, como a síntese granular ou a micromontagem (ROSSETTI; MANZOLLI, 2019, p.206-209). A síntese granular é um procedimento automatizado que produz nuvens sonoras controladas por uma aglutinação algorítmica de uma grande quantidade de grãos, com as suas próprias formas de onda e envelopes de amplitude (ROADS, 2001, p.86), procedimento muito ligado à música de Barry Truax e Curtis Roads dos anos 1990 e 2000. A micromontagem, por sua vez, se aproxima da edição manual realizada por Xenakis em Concret $\mathrm{PH}$, porém realizada em ambiente digital. Compositores como Horacio Vaggione fazem uso extensivo dessa técnica, um

$7 \quad$ Original: "Tout son est une intégration de grains, de particules élémentaires sonores, de quanta sonores. Chacun de ces grains élémentaires a une triple nature: la durée, la fréquence et l'intensité. Tout son, toute variation sonore même continue est conçue comme un assemblage de grains élémentaires suffisamment nombreux et disposés dans le temps d'une façon adéquate" (XENAKIS, 1962, p.61). 
tipo de montagem realizada em escalas temporais inferiores a 100 milissegundos, com procedimentos de cortes, reversões, fades etc.

\section{Ferramentas de composição assistida por computador}

Tendo em vista as descrições apresentadas sobre os processos de espacialização em ambissonia e os modelos de criação sonora ondulatório e granular, apresento a seguir dois exemplos de ferramentas de criação musical assistida por computador que se baseiam nessas abordagens. A primeira ferramenta, ligada ao paradigma ondulatório, combina a síntese FM e a espacialização do espectro produzido. A segunda ferramenta, ligada ao paradigma granular, combina a síntese granular e a espacialização dos grãos em diferentes tamanhos associados aos harmônicos espaciais da ambissonia de ordem superior. Em ambos os exemplos foi utilizada a ambissonia de terceira ordem.

\subsection{Síntese FM e espacialização do espectro}

A partir dessa ferramenta, tive a intenção de propor uma maneira de integrar o espaço ao espectro do som, ressaltando as características individuais dos parciais contidos no som resultante da síntese FM. De maneira empírica, através da escuta, percebe-se que, quando o mesmo som gerado pela síntese concentra-se em um ou dois canais (mono ou stereo), os parciais desse som se comprimem em uma imagem frontal. Trata-se de uma proposta de difusão espectral em que, a partir da espacialização de bandas de frequência do espectro de um som numa sala com preenchimento do espaço do ouvinte em $360^{\circ}$ (já que a audição, ao contrário da visão, nos envolve totalmente), temos uma imagem imersiva do som produzido, ao se posicionar cada banda frequencial em um determinado local do espaço. Por meio dessa imagem pode-se distinguir com mais clareza as qualidades sonoras dos parciais individualmente (altura, intensidade, rugosidade etc.), além da imagem totalizante do timbre produzido pela síntese que ressoa no espaço da sala de difusão.

A síntese FM ou síntese por modulação de frequência é uma modulação entre dois sinais (uma onda portadora e outra modulante), que produz modificações espectrais no som produzido ao longo de seu envelope. Na síntese FM, a taxa de variação da frequência da onda portadora varia de acordo com a frequência da onda modulante, e esse valor é conhecido como índice de modulação. Uma informação importante a respeito do índice de modulação é que, caso ele seja um número racional, são gerados espectros harmônicos (cujos parciais se relacionam proporcionalmente à frequência fundamental). Caso o índice de modulação seja um número irracional, são produzidos espectros inarmônicos com distribuições diversas entre os parciais entre si, assim como entre os parciais e a frequência fundamental (CHOWNING, 1973, p.527).

Na Fig. 1 apresento o patch criado em Max/MSP que realiza a combinação entre síntese FM e espacialização em ambissonia, que divido em quatro módulos para uma melhor compreensão do seu funcionamento. 


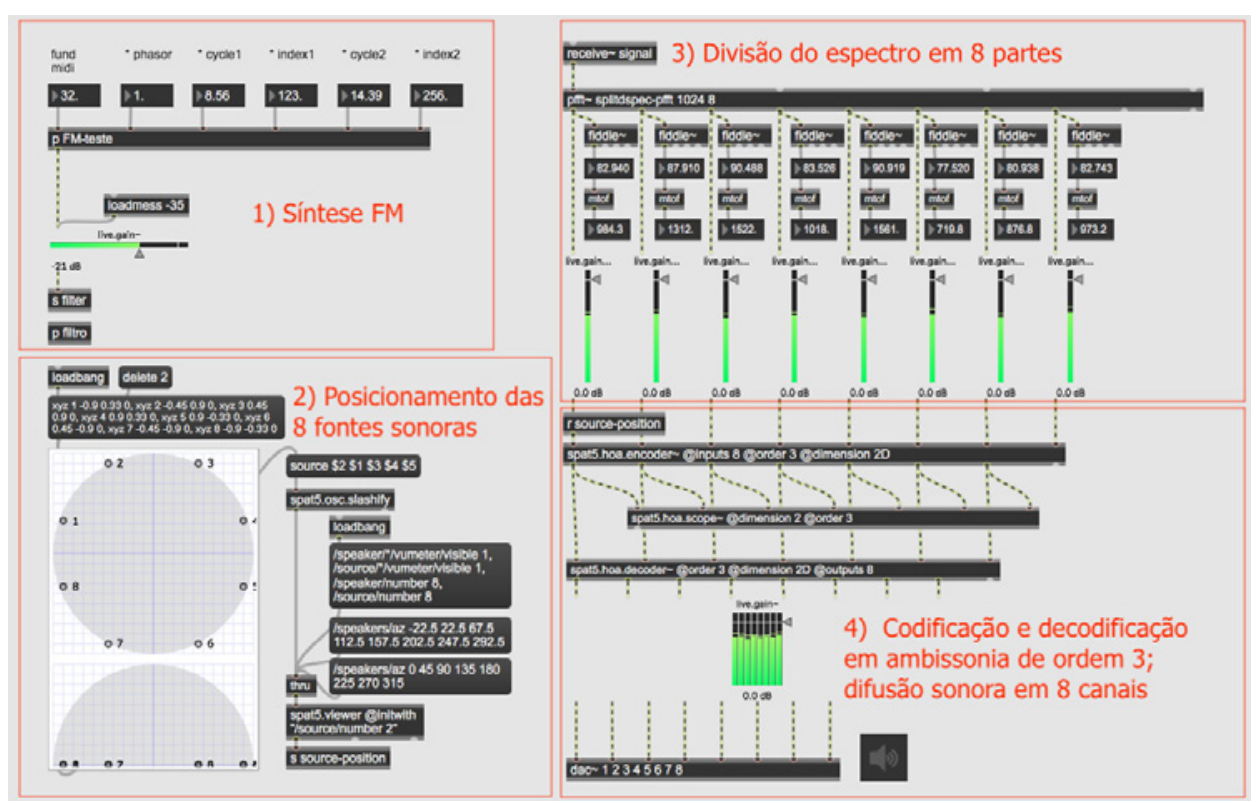

Fig. 1: Patch combinando síntese FM e espacialização em ambissonia de ordem 3.

No módulo 1, posição esquerda/acima da Fig. 1, temos a síntese FM cuja programação foi incluída em um subpatch que não reproduziremos aqui, o qual opera com uma onda portadora e duas ondas modulantes e seus respectivos índices de modulação. A síntese funciona com a definição de seis parâmetros: 1) frequência fundamental (em valor Midi); 2) frequência da onda portadora; 3) frequência da onda modulante 1; 4) índice de modulação 1 ; 5) frequência da onda modulante 2 ; e 6) valor do índice de modulação 2. Os valores das ondas portadora e modulante 1 e 2 são definidos proporcionalmente em função do valor da frequência fundamental escolhida. Os valores aqui utilizados foram os seguintes: frequência fundamental com valor Midi 32 (equivalente a $51,91 \mathrm{~Hz}$ ou Sol\# 1), onda portadora em formato de dente de serra (phasor) com esse mesmo valor frequencial (frequência fundamental multiplicada por 1), onda modulante $1 \mathrm{em} 444,38 \mathrm{~Hz}(51,91 \times 8,56)$, índice de modulação 1 no valor de 123 , onda modulante 2 em 747,03 Hz (51,91 X 14,39) e índice de modulação 2 no valor de 256.

No módulo 2 (esquerda/abaixo) temos o módulo de espacialização com 8 fontes sonoras numeradas de 1 a 8 , posicionadas em duas dimensões (2D), com suas localizações no espaço definidas pelo objeto ambmonitor da biblioteca ICST Ambisonics. Nesse objeto, o círculo completo indica a posição das fontes sonoras num plano 2D, e a metade do círculo logo abaixo indica a altura da posição das fontes sonoras, no caso de uma espacialização em 3D. No exemplo da Fig. 1, as posições das oito fontes sonoras foram definidas de maneira equidistante, no limite da área do círculo.

No módulo 3 (direita/acima) realiza-se a divisão do espectro do som produzido pela síntese FM em 8 parciais. O objeto pfft splitdspec combina a transformada de Fourier com o objeto el.splitspec da biblioteca Lyon/Potpourri 3.0 e decompõe o espectro sonoro e diferentes parciais com informações de frequência, amplitude e fase. $\mathrm{Na}$ saída do objeto temos as 8 bandas frequenciais separadas do som original que são encaminhadas para 8 objetos live.gain (faders) que permitem a programação de suas amplitudes separadamente. Cada saída também é enviada a um objeto fiddle que for- 
nece os valores das alturas individualmente em valores Midi que, a seguir, são convertidos em valores frequenciais pelos objetos mtof (midi to frequency). Nesse exemplo, o som produzido pela síntese FM é dividido em oito partes com seus valores em frequência e suas respectivas alturas musicais informados na Tab. 1.

\begin{tabular}{|c|c|c|}
\hline Parcial & Frequência (em Hz) & Altura aproximada \\
\hline 1 & 984,3 & Si 5 \\
\hline 2 & 1312 & Mi 6 \\
\hline 3 & 1522 & Fá $\$ 6$ \\
\hline 4 & 1018 & Si $_{\ddagger} 5$ \\
\hline 5 & 1561 & Sol 6 \\
\hline 6 & 719,8 & Fá 5 \\
\hline 7 & 876,8 & Lá 5 \\
\hline 8 & 973,2 & Si $\downarrow 5$ \\
\hline
\end{tabular}

Tab. 1: Oito parciais do espectro da síntese FM, seus valores em frequência e alturas aproximadas.

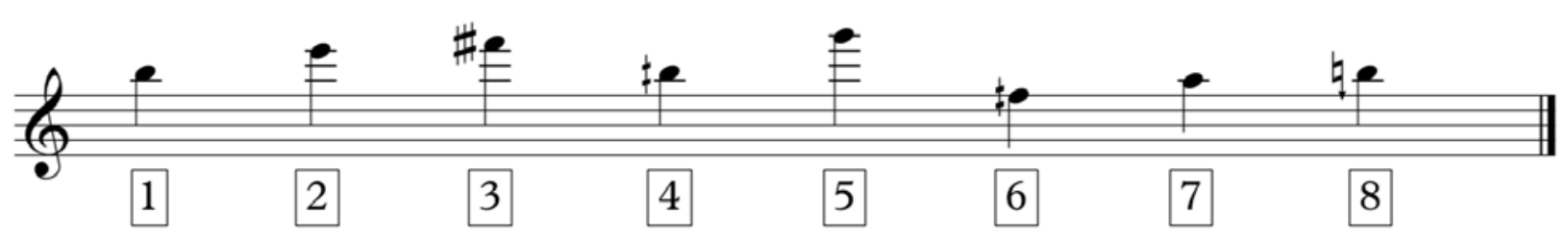

Fig. 2: Alturas aproximadas de oito parciais do espectro da síntese FM.

No módulo 4 (direita/abaixo) temos a codificação dos sinais correspondentes aos 8 parciais da síntese FM para a ordem 3 de ambissonia, realizada pelo objeto spat5. hoa.encoder , da biblioteca SPAT. Esse mesmo objeto recebe a posição de cada fonte sonora no espaço de difusão, enviadas pelo objeto ambmonitor. A seguir, o objeto spat5.hoa.decoder realiza a decodificação do modo de ambissonia de ordem 3 para a difusão em 8 canais.

Observando os processos envolvidos, o que ocorre nesse patch é a decomposição de um som inarmônico produzido por síntese FM em 8 bandas frequenciais com diferentes valores frequenciais e alturas. Cada um desses sinais é codificado para uma espacialização em ambissonia de ordem 3, contendo o harmônico 0 mais os harmônicos 1, 2, e 3, cada qual com seus harmônicos positivos e negativos, totalizando sete harmônicos circulares (correspondentes às sete saídas de áudio do objeto spat5.hoa. encoder ). Cada uma das oito fontes sonoras (os parciais da síntese FM individualmen- 
te) são posicionadas em locais diferentes do espaço de difusão, possibilitando a criação de um espaço sonoro imersivo que é preenchido pelo timbre produzido pela síntese FM. Dessa forma, o ouvinte é envolvido pelo som da síntese, situando-se imerso nesse contexto, com a perceção de uma imagem sonora do timbre produzido espacializada em $360^{\circ}$. No exemplo abordado, as fontes sonoras ficam imóveis no espaço de difusão. No entanto, mais adiante apresentarei um exemplo prático de uma composição na qual as fontes se movem no espaço.

\subsection{Síntese granular e o preenchimento do espaço pelos grãos}

Essa ferramenta realiza um tipo de síntese granular a partir de diferentes partes do espectro sonoro, sendo que esse processo da síntese ocorre entre a codificação e a decodificação do modo de ambissonia. Assim, a síntese granular está de fato imbricada à espacialização na medida em que os valores das variáveis da síntese correlacionam-se com os harmônicos circulares da ambissonia. A implementação do processo de síntese granular incorporado ao modo de espacialização baseou-se nos objetos hoa.fx.grain e hoa. syn.grain da biblioteca HOA (SĖDES; GUILLOT; PARIS, 2014), e os detalhes serão discutidos ao longo desse tópico. O patch em Max/MSP dessa ferramenta pode ser visualizado na Fig. 3 a seguir.

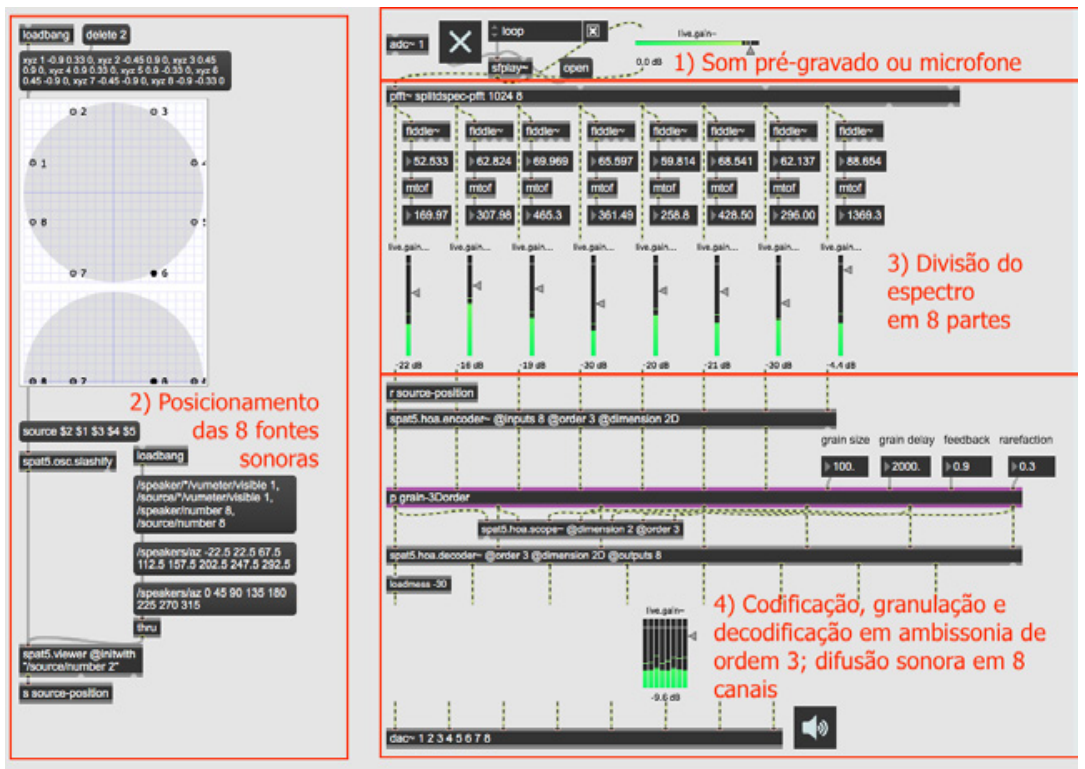

Fig. 3: Visual do patch em Max/MSP de granulação espectral e espacialização em ambissonia.

O patch proporciona, inicialmente, o fatiamento do espectro do som de entrada (som pré-gravado ou captado ao vivo por um microfone) em oito bandas frequenciais e, a seguir, realiza a granulação de cada uma das oito bandas separadamente. Portanto temos, concomitantemente, uma difusão espectral e uma difusão por granulação. Dessa forma, é importante ressaltar que se opera, ao mesmo tempo, dentro do paradigma ondulatório e do paradigma granular, reforçando a ideia de que esses paradigmas são complementares, e não excludentes entre si. No processo composicional, justamente é 
interessante trabalhar com ambos os paradigmas por superposição ou justaposição, já que estas produzem timbres ou texturas com qualidades espectro-morfológicas distintas.

No módulo 1 do patch (Fig. 3) temos a entrada de som para o processamento, seja um som pré-gravado, seja um som captado pelo microfone. No exemplo abordado utilizamos como fonte sonora o som pré-gravado do efeito de growl numa tuba, técnica de execução em que o instrumentista realiza vocalizações no bocal do instrumento, alterando o timbre do som produzido. Os módulos 2 (determinação da posição das 8 fontes sonoras no espaço de difusão) e 3 (divisão do espectro sonoro em 8 partes com controle individual das intensidades) funcionam de maneira idêntica ao exemplo anterior, não necessitando de novas explicações sobre o seu funcionamento.

Nesse exemplo, o módulo 4 merece especial atenção. Os processos de codificação e decodificação da ambissonia de terceira ordem também ocorrem da mesma maneira que no exemplo anterior, no entanto observemos que há um subpatch denominado grain-3Dorder posicionado entre os objetos spat5.hoa.encoder e spat5.hoa.decoder . Este objeto possui sete entradas e sete saídas de áudio, além de quatro entradas à direita para os valores numéricos dos quatro parâmetros da síntese granular: tamanho de grão (grain size), tempo de delay (grain delay), feedback e taxa de rarefação (rarefaction). Veremos que esses valores se alternam durante a granulação dos sinais de áudio relativos aos diferentes harmônicos esféricos (conforme detalhamento apresentado na Tab. 2). Na Fig. 4 observa-se o conteúdo desse subpatch.

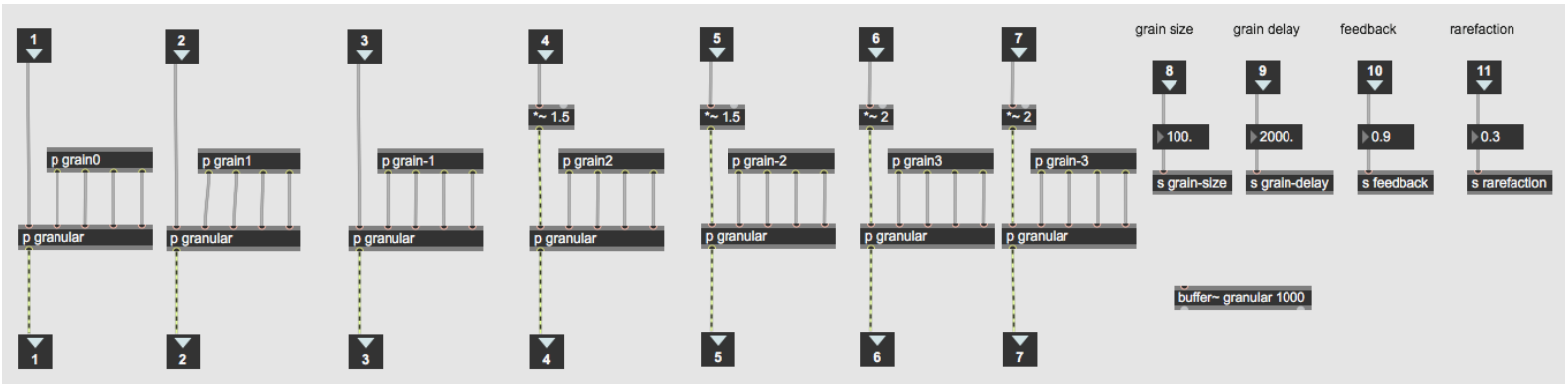

Fig. 4: Subpatch síntese granular em ambissonia de terceira ordem.

De acordo com a ordem 3 de ambissonia na qual temos os harmônicos circulares $(0,0),(1,-1),(1,1),(2,-2),(2,2),(3,-3)$ e $(3,3)$, totalizando 7 , realizam-se sete processos de síntese granular diferentes, cada qual com sua sonoridade resultante enviada para as saídas do subpatch (de 1 a 7) e, a seguir, para a decodificação do modo de ambissonia. Ainda temos, para cada entrada, outros dois subpatches relacionados, sendo eles o $p$ granular (Fig. 4), que promove o processo da síntese (não entraremos em detalhes sobre o seu funcionamento), e os $p$ grain ( 0 a 3 ). Estes últimos realizam os cálculos de proporcionalidade dos valores de entrada das quatro variáreis da síntese, que são diferentes para cada conjunto de harmônicos circulares. A partir dos quatro valores utilizados no exemplo de síntese abordado (tamanho do grão: 100 ms; tempo de delay: 2000 ms; feedback: 0,9; taxa de rarefação: 0,3), os valores dos parâmetros da síntese granular para cada harmônico circular são apresentados na Tab. 2. De acordo com essa tabela, enquanto o tamanho do grão e o tempo de delay decrescem dos harmônicos 0 ao 3, os 
valores de feedback e taxa de rarefação crescem. A proporcionalidade dessas modificações está descrita entre parênteses, sempre em relação aos valores de entrada, e são calculados automaticamente.

\begin{tabular}{|c|c|c|c|c|c|}
\hline Parâmetros & $\begin{array}{c}\text { Valores de } \\
\text { entrada }\end{array}$ & $\begin{array}{c}\text { Harmônico } \\
\text { esférico 0 }\end{array}$ & $\begin{array}{c}\text { Harmônico } \\
\text { esférico 1 }\end{array}$ & $\begin{array}{c}\text { Harmônico } \\
\text { esférico 2 }\end{array}$ & $\begin{array}{c}\text { Harmônico } \\
\text { esférico 3 }\end{array}$ \\
\hline Tamanho do grão (ms) & 100 & $100(1 / 1)$ & $66,67(2 / 3)$ & $50(1 / 2)$ & $33(1 / 3)$ \\
\hline Tempo de delay $(\mathrm{ms})$ & 2000 & $2000(1 / 1)$ & $1500(3 / 4)$ & $1200(3 / 5)$ & $1000(1 / 2)$ \\
\hline Feedback & 0,9 & $0,45(1 / 2)$ & $0,594(2 / 3)$ & $0,72(4 / 5)$ & $0,9(1 / 1)$ \\
\hline Taxa de rarefação & 0,3 & $0,3(1 / 1)$ & $0,5(+0,2)$ & $0,6(+0,3)$ & $0,7(+0,4)$ \\
\hline
\end{tabular}

Mas qual seria a diferença entre realizar a síntese granular após a codificação do sinal para o modo de ambissonia ou antes de fazê-lo (realizando a síntese antes da codificação)? A resposta a essa pergunta passa mais por questões estéticas em relação ao resultado sonoro do que pelo fato de uma maneira ser mais vantajosa que a outra. $\mathrm{Na}$ realidade, a segunda opção também já foi utilizada na aplicação desses processos na composição de Imagens transdutivas e na construção do instrumento digital utilizado nessa composição, assunto que será discutido no próximo item. Caso realizemos a síntese granular antes da codificação para o modo de ambissonia, trabalharemos com uma fonte pontual de síntese granular passível de ser posicionada e movida no espaço de difusão. Esse seria o caso mais comum de espacialização e teríamos apenas um valor determinado para cada variável da síntese (tamanho do grão, tempo de delay, feedback e taxa de rarefação).

Porém, caso utilizemos a síntese granular da maneira que foi descrita acima, teremos outro resultado que incorpora o princípio da ambissonia e permite gerar campos sonoros imersivos. Pode-se observar que para os sinais de áudio de cada harmônico esférico atribuem-se valores de parâmetros diferentes. Assim, buscou-se produzir uma síntese sonoramente mais rica em relação à variedade morfológica dos grãos produzidos. De fato, se utilizarmos diferentes parâmetros de síntese para cada harmônico esférico, haverá maior variação na totalidade da morfologia dos grãos produzidos. Além disso, há a percepção de uma movimentação desses grãos no espaço pelo ouvinte. Essa perceção de movimentação não ocorre por uma programação de movimento das fontes pontuais, mas, sim, pela percepção das diferenças de amplitude e bandas de frequência dos grãos produzidos criando um campo sonoro difuso com muitas reflexões, no qual não se tem a definição da localização da fonte sonora original. Nesse sentido, temos a percepção de muitas imagens sonoras de movimentos diferentes que, em sua somatória, nos fornecem uma imagem totalizante que contém blocos de espaço/tempo nos quais todas as imagens percebidas se incluem ${ }^{8}$. 


\section{A construção de um instrumento para criação e difusão de peças em diferentes sistemas de espacialização}

O intuito do patch em Max/MSP que apresento neste item foi a construção de um instrumento que realiza diferentes processamentos e espacialização sonora, adaptável a diferentes sistemas com diferentes características, como quanto ao número de alto-falantes e projeção sonora em 2D ou 3D. O instrumento apresenta alguns módulos de síntese e processamento que discutiremos logo a seguir, além de incorporar as ferramentas de síntese FM e síntese granular apresentadas no item anterior. Como resultado, a peça experimental Imagens transdutivas ${ }^{9}$ foi composta, criada a partir desse sistema elaborado, com difusão em oito canais em ambissonia de terceira ordem. $O$ mesmo instrumento deverá ser utilizado na composição de outras peças, com diferentes abordagens. A visão geral do patch é apresentada na Fig. 5.

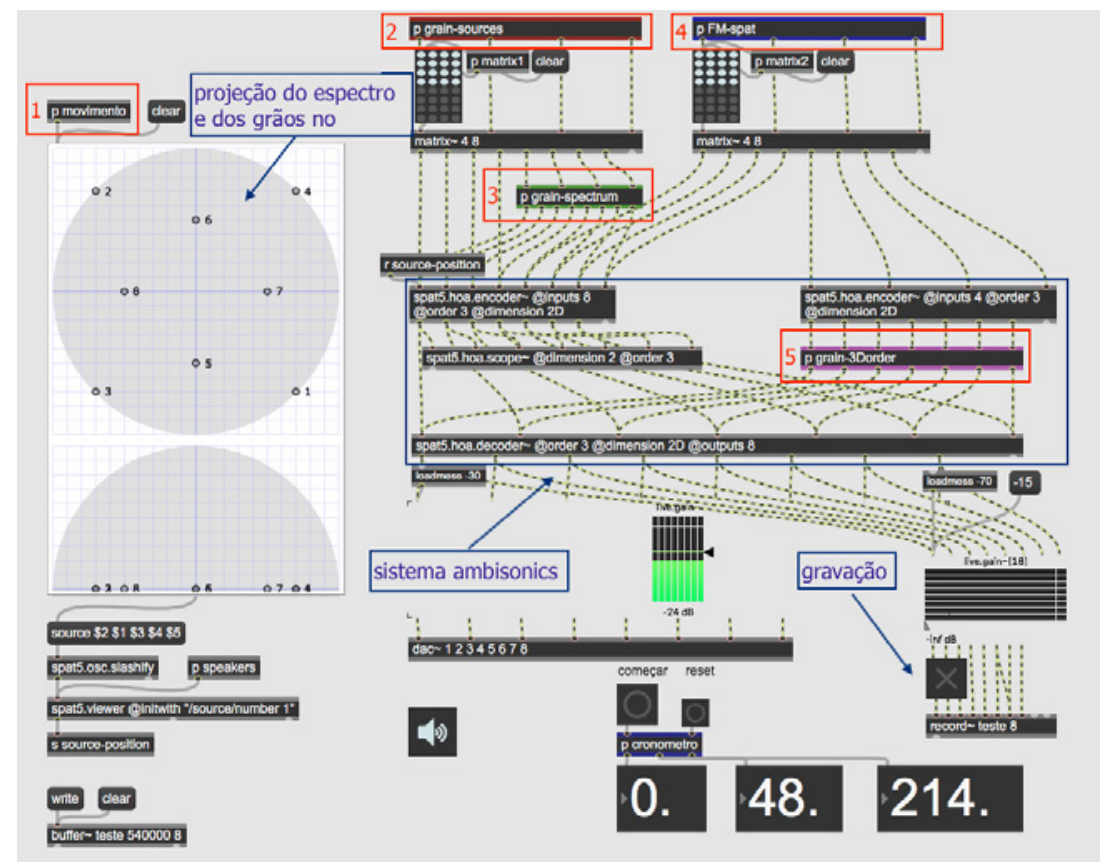

Fig. 5: Visão geral do patch de Imagens transdutivas.

Estes são os módulos (subpatches) incluídos no patch principal, numerados de 1 a 5: 1) $p$ movimento; 2) p grain-sources; 3) $p$ grain-spectrum; 4) $p$ fm-spat; e 5) $p$ grain3D-order. Ademais, destaca-se no patch a presença dos seguintes objetos já discutidos anteriormente: a) ambimonitor, à esquerda, na Fig. 5, com a posição e o movimento de oito fontes sonoras; b) spat5.hoa.encoder e spat5.hoa.decoder , responsáveis pela codificação e decodificação da ambissonia de ordem superior (nesse caso, de terceira ordem); e c) módulo de gravação em oito canais, à direita/abaixo na Fig. 5 (objeto record ), que possibilita a gravação em tempo real do resultado sonoro da peça.

\footnotetext{
sonia já foi realizado por nós e será divulgado em outro trabalho (ROSSETTI; MANZOLLI, 2020, no prelo). Portanto, não incluiremos os resultados neste artigo. Em relação à essa questão, pode-se afirmar que, quanto maior for a ordem de ambissonia utilizada, maior será a percepção de movimento dos grãos por um ouvinte.

9 Neste link é possível baixar a redução stereo de Imagens transdutivas, além do patch em Max/MSP da Fig. 5 sem os arquivos de áudio utilizados na síntese granular: https://drive.google.com/drive/folders/1NSUWD1_2dxOoPxQmgdi3sRXBEfdKXgbf?usp=sharing.
} 
1) p movimento: Aqui pode-se definir a posição das oito fontes sonoras no espaço de difusão,além do movimento que estas fontes podem realizar nesse espaço. Para cada fonte sonora definem-se os valores das coordenadas $\mathrm{X}$ e $\mathrm{Y}$, que determinam seus respectivos pontos no espaço. As movimentações das fontes sonoras podem ser escritas em formato de partitura numérica, indicando-se os valores das coordenadas das posições iniciais e finais, além do tempo de realização do movimento (em milissegundos), em retas ou curvas. Na Fig. 6 há um exemplo de partitura numérica, cujo acionamento é feito por letras e números do teclado do computador, sendo que as letras (de $\mathrm{A}$ a J) definem a posição das fontes sonoras, e os números (de 1 a 5 ), os movimentos dessas fontes no espaço.

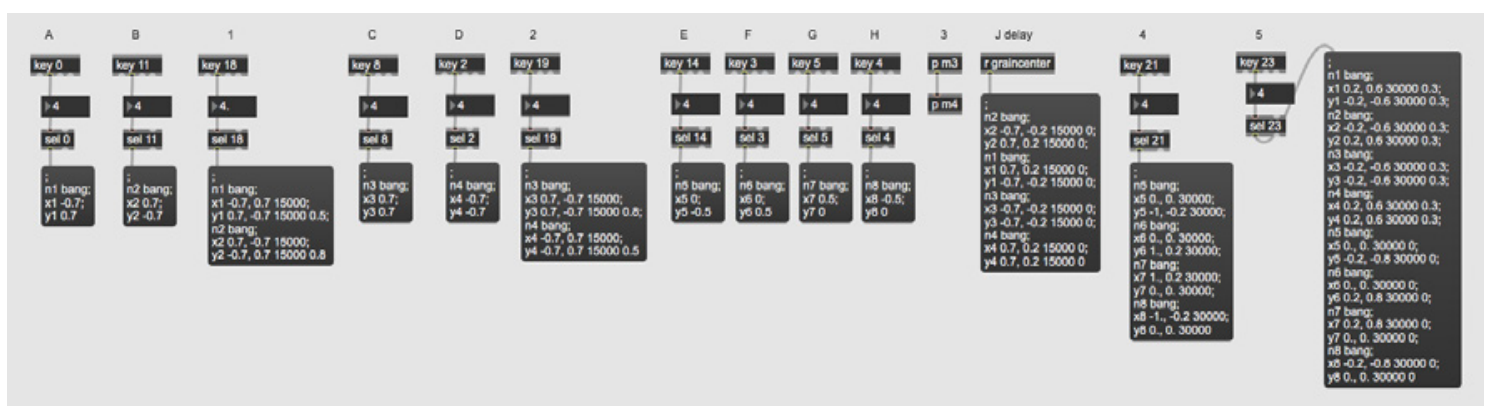

Fig. 6: Partitura com variáveis que definem posição e movimento das fontes sonoras no espaço de difusão.

2) p grain-sources: Estes são os quatro módulos para a realização de síntese granular a partir de sons pré-gravados. Cada módulo é independente e operável a partir de quatro parâmetros de síntese: tamanho do grão, tempo de delay, feedback e taxa de rarefação. Na saída de cada módulo de síntese granular há um outro módulo que realiza transposições dos sons sintetizados ( $p$ pitchshift), com a utilização do objeto pitchshift . Esses quatro módulos produzem quatro tipos diferentes de síntese granular a partir de diferentes fontes sonoras pré-gravadas, que são numeradas de 1 a 4 , e cujas posições e movimentações no espaço de difusão são definidas pelo objeto ambmonitor e programáveis a partir das partituras numéricas (Fig. 6). Nesse módulo há uma espacialização dos sons produzidos pela síntese granular de forma pontual, sendo que a possibilidade de imersão sonora pelo ouvinte se dá pela fusão da sonoridade das quatro fontes, e não por sua percepção individual.

3) p grain-spectrum: Além da possibilidade de enviar o som resultante dos quatro processos de síntese granular diretamente para a sua espacialização, pode-se também enviá-los para o módulo chamado $p$ grain-spectrum, que promove a separação de cada uma das quatro fontes de síntese granular em duas bandas frequenciais, totalizando oito bandas e obtendo uma imagem sonora de natureza imersiva dos processos de síntese granular realizados. A separação do espectro dos processos de síntese granular em duas bandas frequenciais é feita a partir da FFT, além da utilização do objeto el.splitspec , o qual realiza a divisão do espectro, nesse caso em duas bandas. Na Fig. 7 apresento o módulo $p$ grain-spectrum e o processamento FFT no objeto pfft pfft_splispec. 


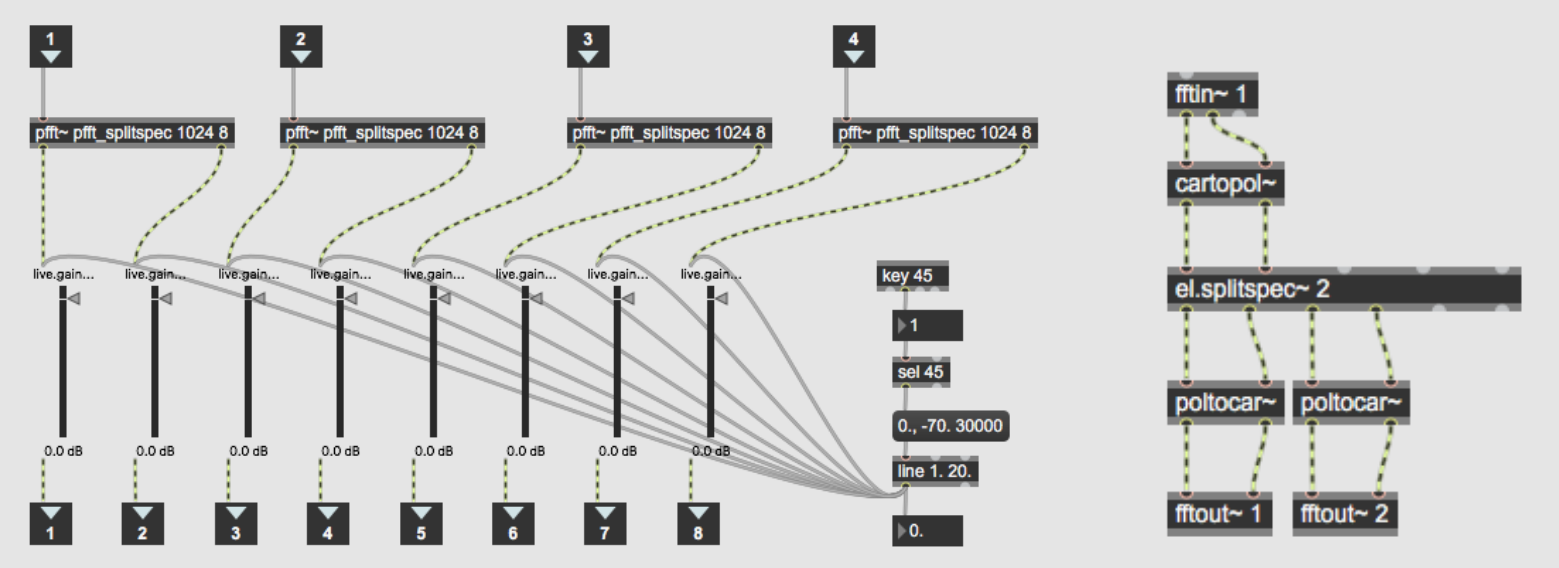

Fig. 7: Interior do módulo p grain-spectrum (à esquerda) e processo FFT de divisão do espectro (à direita).

4) p FM-spat: Este módulo contém um sintetizador FM cujo som resultante da síntese é enviado a outro objeto pfft splitspec, que, como foi visto, promove a separação do espectro em diferentes bandas frequenciais, nesse caso, em quatro bandas (analogamente à ferramenta apresentada no item 5.1). As quatro bandas frequenciais do espectro do som produzido pela síntese FM correspondem às fontes sonoras 5 a 8 e podem ser enviadas a dois locais diferentes: 1) ao objeto spat5.hoa.encoder à esquerda, com oito entradas, em que a posição e o movimento no espaço de difusão podem ser visualizadas no objeto ambmonitor e controladas por partitura numérica; e 2) ao objeto spat5.hoa.encoder à direita, com quatro entradas e sete saídas, correspondentes à codificação da ambissonia de ordem 3, que está conectada ao subpatch $p$ grain-3Dorder cujo conteúdo já foi abordado no item 5.2, capaz de realizar a síntese granular dos sons produzidos por síntese FM já codificados em modo de ambissonia.

5) $p$ grain-3D-order: Módulo idêntico à ferramenta abordada no item 5.2. O objetivo dessa ferramenta foi a construção de um instrumento que contém diferentes processos de síntese sonora (granular e FM), além de diferentes maneiras de promover a espacialização dos sons produzidos, seja através de fontes pontuais que se movimentam no espaço, seja através da exploração do sistema de ambissonia e sua capacidade de produzir campos sonoros imersivos em que o espectro ou os grãos se movimentam no espaço de maneira difusa, ou seja, sem que seja possível definir a posição espacial exata das fontes sonoras.

\section{Experimento composicional: Imagens transdutivas}

No experimento composicional Imagens transdutivas, procurou-se trabalhar as diferenciações entre sons contínuos e descontínuos (oriundos das sínteses FM e granular) e espacializações pontuais e imersivas. O resultado dessas variações de morfologia sonora e espacialização teve uma incidência que determinou a forma da peça composta, que pode ser dividida em seis partes com seus eventos espectrais e espaciais descritos a seguir.

Mais adiante, na Fig. 8, apresenta-se uma representação gráfica da forma da obra Imagens transdutivas, com sua divisão formal em seis partes definida a partir de varia- 
ções de morfologia sonora. A representação gráfica apresentada da Fig. 8 é denominada volume (ROSSETTI; MANZOLLI, 2019), sendo definida por valores do centroide e seu espalhamento espectral (spectral spread) determinado pela largura da banda, além dos valores do loudness representados pelas cores (numa escala do lilás ao vermelho, passando pelos tons de verde e amarelo). Convém lembrar que o eixo $X$ contém os valores do tempo (em minutos), e o eixo $Y$, das frequências (de 0 a $10.000 \mathrm{~Hz}$ ).

1) De 0' a 1'40": Fontes pontuais de síntese granular (numeradas de 1 a 4) que foram realizadas a partir de gravações de sons de instrumentos acústicos (multifônico de clarinete, violino em tremolo sul ponticello, oboé em frullato e tuba com efeito de growl). A síntese granular apresenta um valor baixo do tamanho do grão $(20 \mathrm{~ms})$ e alta taxa de rarefação (0.8). Com isso é criada uma nuvem sonora bastante descontínua e rarefeita. A princípio, as fontes sonoras ficam estáticas e depois entram em movimento.

2) De 1'40" a 3'55": Há a sobreposição de sons da síntese granular (descontínuos) com um som da síntese FM (contínuo) que é segmentado em quatro bandas de frequências (fontes sonoras 5 a 8). As partes da síntese FM são espacializadas em diferentes pontos do espaço de difusão com diversas movimentações das oito fontes sonoras virtuais.

3) De 3'55" a 4'50": Aqui há a mesma textura sonora do trecho anterior e variação dos parâmetros da síntese FM (aumento dos valores dos dois índices de modulação e das frequências das ondas modulantes).

4) 4'50" a 5'05": Há a presença de um clímax sonoro com congelamento da variação dos parâmetros da síntese $\mathrm{FM} \mathrm{e}$, logo a seguir, um corte abrupto com silêncio expressivo.

5) 5'05" a 6'30": Ocorre o retorno da sonoridade da síntese granular com fontes pontuais apresentando grãos que se tornam gradualmente maiores (transição no sentido do descontínuo para o contínuo), além de uma nova síntese granular imersiva (processada entre a codificação e a decodificação do modo de ambissonia) e realizada a partir dos sons da síntese FM com gradual redução do tamanho dos grãos e aumento da taxa de rarefação (reforçando a descontinuidade dos sons). Ao final desse trecho, o som da segunda síntese granular (oriunda da síntese FM) também desaparece de forma gradual.

6) 6'30" a 8'05": O espectro da primeira síntese granular (fontes instrumentais pontuais) é segmentado e espacializado em oito pontos distintos que se movem no espaço de difusão do centro para as extremidades. A síntese apresenta grãos de tamanho bastante alto e taxa de rarefação nula, produzindo sons extremamente contínuos que reforçam a sensação de estabilidade.

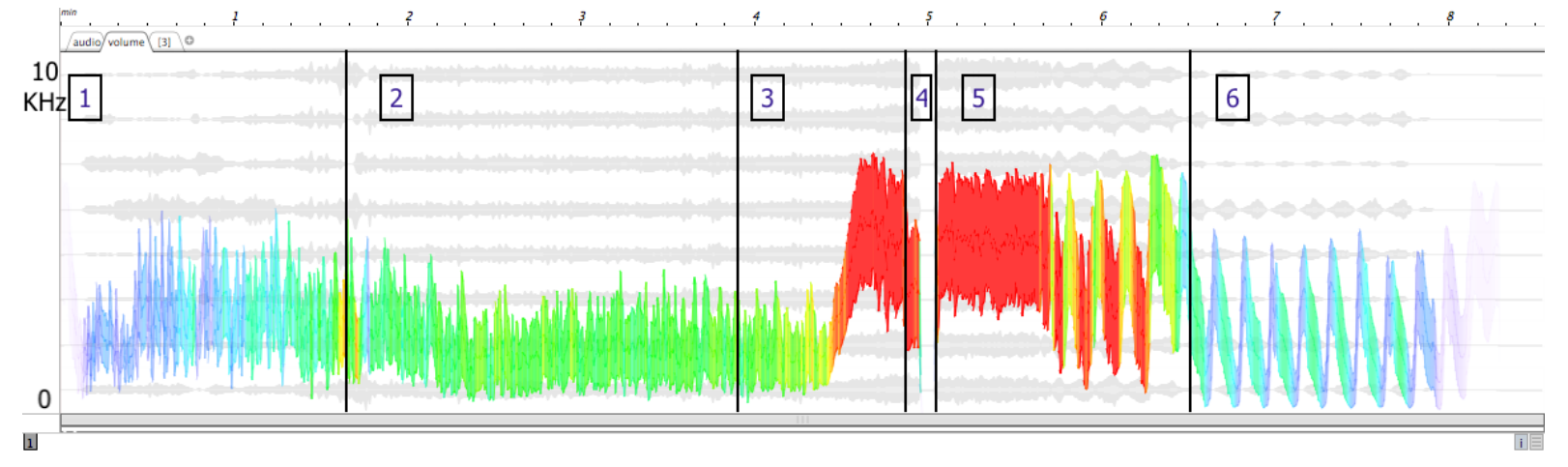

Fig. 8: Representação gráfica do volume com a forma de Imagens transdutivas e sua segmentação. 
Gilles Deleuze (2018), em uma discussão sobre a teoria das imagens de Henri Bergson, coloca algumas questões sobre a percepção do movimento, afirmando que é a continuidade do movimento que descreve a figura percebida ou sua forma. $\mathrm{O}$ movimento teria duas faces: "[...] ele é o que se passa entre objetos ou partes; por outro, o que exprime a duração ou o todo" (DELEUZE, 2018, p.26). Portanto, o movimento está ligado tanto à percepção do espaço como do tempo. Por essa razão, pode-se haver ao menos três tipos de imagens: 1) imagens instantâneas, que remetem ao espaço; 2) imagens-movimento ou cortes móveis de duração; e 3) imagens-tempo ou imagens com densidade e volume (DELEUZE, 2018, p.27). O conjunto infinito de todas as imagens (instantâneas) constitui um plano de imanência ou sua matéria, que é a identidade das imagens-movimento ou blocos de espaço-tempo (DELEUZE, 2018, p.103).

Ao presenciarmos em uma difusão sonora a projeção do espectro em movimento em diferentes lugares do espaço, perceptivamente inúmeras imagens são produzidas em nossa consciência, blocos de espaço-tempo que nos fornecem uma imagem totalizante do fenômeno percebido. O universo interior do som que, quando percebido a partir de uma fonte pontual, nos é revelado de forma condensada, quando é projetado no espaço, adquire uma nova configuração imersiva em que novos detalhes se revelam. Essa abertura para o conteúdo microtemporal do som seria uma das grandes vantagens da projeção do espectro do som no espaço, proporcionando uma forma diferente de audição detalhada dos fenômenos mais sutis, que de outra maneira poderiam estar encobertos ou mascarados.

Do ponto de vista perceptivo, é bastante claro que a operação de granulação dá ênfase à percepção do universo microtemporal do som, ao realizar o fatiamento do som em pequenas partes com durações em milissegundos. Porém, quando nos situamos dentro do paradigma ondulatório (que é da ordem da continuidade), acredito que a percepção também pode se dar no nível microtemporal, principalmente quando há a divisão do espectro em diferentes bandas frequenciais que são difundidas no espaço através de fontes independentes posicionadas em diferentes locais. A divisão espectral do som em uma série de parciais envolve uma operação FFT que é dependente de uma operação de "janelamento", operação esta de caráter microtemporal. A isto junta-se o fato de que as frequências separadas que foram obtidas não são alturas ou notas musicais, já que estas últimas são muito mais complexas, sendo o resultado de um aglomerado de parciais com uma certa "ordem". A partir de uma visão mais global, frequências, por definição, são ciclos por segundo e, nesse sentido, também possuem em si a ideia de tempo ou duração. Uma frequência de $1.000 \mathrm{~Hz}$ pressupõe uma vibração de mil ciclos por segundo que produz um estímulo sonoro específico em nosso sistema auditivo. Ou seja, por essa razão, ao tratarmos das frequências, acredito que também estaremos nos referindo ao universo do microtempo.

Voltando às imagens instantâneas percebidas, estas se conectariam entre si como um processo transdutivo, tal como uma reação em cadeia que se propaga entre os elementos próximos, formando um conjunto de imagens que caracterizaria o movimento do espectro dos sons. Ao mesmo tempo, a percepção que organiza a macroforma desses inúmeros elementos de menor escala seria dada por uma energia moduladora 
contínua que condensa essa informação em blocos com maior estabilidade (SIMONDON, 2010, p.159-176). No caso de sistemas de áudio imersivos em 2D ou 3D, a forma percebida seria constituída por blocos de espaço-tempo totalizantes, em $360^{\circ}$.

\section{Considerações finais}

Procurou-se apresentar uma maneira de conceber o espaço como categoria operatória na composição musical de obras eletroacústicas, sejam elas acusmáticas ou mistas. Como discutido, essa categoria muitas vezes na história da música perdeu relevância na elaboração musical, principalmente com a adoção do palco italiano como principal configuração de salas de concerto. O espaço sonoro imersivo com fontes sonoras posicionadas de forma a envolver o público (sejam elas instrumentos musicais ou alto-falantes) teve sua retomada após os anos 1950, primeiramente com a composição de obras eletroacústicas em formato multicanal, influenciando logo a seguir a música instrumental.

A proposta apresentada buscou, além de conceber o espaço como categoria composicional manipulável, apresentar uma possibilidade de se projetar o espectro do som no espaço de difusão sonora. É uma maneira na qual o tempo do som e sua morfologia são segmentados (através da sua divisão em grãos ou em parciais) e enviados a diferentes locais do espaço. É importante ressaltar que, por essa divisão, o espectro do som se apropria do espaço amplificando as suas propriedades intrínsecas, produzindo na percepção uma imagem sonora totalizante que pode revelar detalhes da morfologia interna dos sons projetados.

A diferenciação entre o contínuo e o descontínuo, ou entre os paradigmas ondulatório e granular, não necessita ser pensada à maneira de uma oposição dialética, mas, sim, em termos de complementariedade, tal como encontramos na onda de matéria de Louis De Broglie (1992), na qual toda matéria apresentaria características ondulatórias e corpusculares, comportando-se de um ou outro modo, dependendo do experimento específico. No discurso musical, essa complementariedade, por sua vez, pode ser estruturada no tempo e no espaço por justaposição (sucessão de timbres ou estruturas sonoras) ou superposição (coincidência temporal entre essas estruturas). No caso da superposição de sons contínuos e descontínuos, o pensamento composicional pode envolver ainda a distribuição desses sons no espaço, o que resultaria em uma possibilidade de escuta mais detalhada do conteúdo interno desses sons, escuta esta dependente da localização no espaço tanto do ouvinte quanto das fontes sonoras virtuais.

O campo de pesquisa relativo à composição musical, explorando o espaço como possibilidade operatória, tanto na música eletroacústica como na música instrumental, é muito amplo e sugere múltiplas abordagens. A abordagem com suporte tecnológico que foi apresentada é apenas uma dessas possibilidades. Quando essas abordagens são relacionadas a um estudo da percepção do som no espaço, o campo de estudo aumenta consideravelmente. Dentre os nossos sentidos, é possível que a audição seja um dos mais complexos e com muitas questões ainda em aberto, principalmente quando se aborda uma problemática relacionada ao espaço. Nesse contexto, um trabalho experi- 
mental envolvendo a composição musical auxiliado por ferramentas tecnológicas pode ter grande valia para um melhor entendimento desses fenômenos.

\section{Referências}

BARREIRO, Daniel. Investigación y creación en música electroacústica: composición y performance con sistemas multicanales e interfaces gestuales. In: QUARANTA, Daniel (org.). Creación musical, investigación y producción académica: desafíos para la música en la universidad. Morelia: Centro Mexicano para la Música y las Artes Sonoras, 2017.

BOULEZ, Pierre. Penser la musique aujourd'hui. Paris: Denoël/Gonthier, 1963.

CHOWNING, John. The synthesis of complex audio spectra by means of frequency modulation. Journal of the Audio Engineering Society, v. 21, n. 7, p. 527-534, 1973.

COLAFRANCESCO, Julien; GUILLOT, Pierre; PARIS, Eliott. Tutoriel de la bibliotèque HOA pour Max/MSP. Paris: Centre de recherche Informatique et Création Musicale/ Université Paris 8, 2015.

DANIEL, Jérôme. Evolving Views on HOA: From Technological to Pragmatic Concerns. In: THE AMBISONICS SYMPOSIUM, 1., 2009, Graz. Proceedings [...]. Graz: Institute of Electronic Music and Acoustics, 2009, p. 1-18.

DANIEL, Jérôme. Spatial sound encoding including near field effect: introducing distance coding filters and a viable, new ambisonic format. In: AES INTERNATIONAL CONFERENCE, 23., 2003, Copenhagen. Proceedings [...]. New York: Audio Engineering Society Press, 2003.

DANIEL, Jérôme; NICOL, Rozenn; MOREAU, Sábastien. Further Investigations on High Order Ambisonics and Wavefield Synthesis for Holophonic Sound Imaging. In: CONVENTION OF THE AUDIO ENGINEERING SOCIETY, 114., 2003, Amsterdam. Proceedings [...]. New York: Audio Engineering Society Press, 2003.

DE BROGLIE, Louis. Recherche sur la théorie des quanta [1924]. Annales de La Fondation Louis De Broglie, v. 17, n. 1, 1992. Disponível em: https://tel.archivesouvertes.fr/tel-00006807. Acesso em: 6 maio 2020.

DELEUZE, Gilles. Cinema 1: a imagem-movimento. São Paulo: Editora 34, 2018 [1983].

FELGETT, Peter. Ambisonics. Part One: General System Description. Studio Sound, London, v. 17, n. 8, p. 20-22, 40, 1975. 
GARAVAGLIA, Javier. Creating Multiple Spatial Settings with "Granular Spatialization" in the High-Density Loudspeaker Array of the Cube Concert Hall. Computer Music Journal, Cambridge, v. 40, n. 4, p. 79-90, 2016.

GERZON, Michael. Ambisonics. Part Two: Studio Techniques. Studio Sound, London, v. 17, n. 8, p. 24-26, 28, 30, 1975.

GRISEY, Gérard. A propos de la synthèse instrumentale. In: GRISEY, Gérard. Écrits ou l'invention de la musique spectrale. Paris: Éditions MF, 2008 [1979]. p. 35-37.

KANACH, Sharon. Music and Architecture by lannis Xenakis. Hillsdale: Pendragon Press, 2008.

LYON, Eric. Multichannel Sound Design. In: INTERNATIONAL COMPUTER MUSIC CONFERENCE, 45., 2019, New York. Proceedings [...]. San Francisco: International Computer Music Association, 2019.

MENEZES, Flo. A espacialidade na música eletroacústica. In: MENEZES, Flo. Atualidade estética da música eletroacústica. São Paulo: Ed. Unesp, 1999. p. 21-31.

NORMANDEAU, Robert. Timbre spatialization: the medium is the space. Organised Sound, Cambridge, v. 14, n. 3, p. 277-285, 2009.

NUNES, Emmanuel. Tempo e espacialidade: em busca dos lugares do tempo. In: ASSIS, Paulo de (org.). Emmanuel Nunes escritos e entrevistas. Lisboa: Casa da Música/Centro de Estudos de Sociologia e Estética Musical, 2011 [1993]. p. 191-210.

ROADS, Curtis. Microsound. Cambridge, MA: MIT Press, 2001.

ROSSETTI, Danilo. A percepção do timbre em Farben Op. 16 n. 3 de Schoenberg: uma abordagem estética e psicoacústica. Revista Música, v. 17. n. 1, p. 292-324, 2017.

ROSSETTI, Danilo. Das imagens à criação de formas sonoras: uma possível epistemologia dos processos de análise e composição com suporte computacional. Revista Vórtex, v. 6, n. 2, p. 1-27, 2018.

ROSSETTI, Danilo. Música: arte temporal. In: SIMPÓSIO BRASILEIRO DE PÓSGRADUANDOS EM MÚSICA, 1., 2010, Rio de Janeiro. Anais [...]. Rio de Janeiro: Unirio, 2010, p. 1017-1026.

ROSSETTI, Danilo. Processos microtemporais de criação sonora, percepção e modulação da forma: uma abordagem analítica e composicional. Tese (Doutorado em Música) - Instituto de Artes, Universidade Estadual de Campinas, Campinas, 2016. 
ROSSETTI, Danilo; MANZOLLI, Jônatas. Analysis of Granular Acousmatic Music: Representation of Sound Flux and Emergence. Organised Sound, v. 24, n. 2, p. 205216, 2019.

ROSSETTI, Danilo; MANZOLLI, Jônatas. Studying the Perception of Sound in Space: Granular Sounds Spatialize in a High-Order Ambisonics System. Revista Opus, v. 26, n. 1, no prelo, 2020.

SCHAEFFER, Pierre; REIBEL, Guy. Solfejo do objecto sonoro. Trad. António de Sousa Dias. Paris: INA-GRM, 2007. Disponível em: https://ears.pierrecouprie.fr/IMG/pdf/ SchaefferSOS_ASD.pdf. Acesso em: 17 fev. 2020.

SCHOENBERG, Arnold. Composition with Twelve Tones. In: SCHOENBERG, Arnold. Style and Idea. New York: Philosophical Library, 1950 [1941]. p. 170-235.

SĖDES, Anne; GUILLOT, Pierre; PARIS, Elliot. The HOA Library, Review and Prospects. In: INTERNATIONAL COMPUTER MUSIC CONFERENCE, 40., 2014, Athens. Proceedings [...]. San Francisco: International Computer Music Association, 2014. p. 855- 860.

SETHARES, William. Tuning, timbre, spectrum, scale. 2. ed. New York: Springer, 2005.

SIMONDON, Gilbert. L'amplification dans les processus d'information. In: SIMONDON, Gilbert. Communication et information: cours et conférences. Chatou: La Transparence, 2010 [1962]. p. 159-176.

SOLOMOS, Makis. De la musique au son: l'émergence du son dans la musique des XXeXXIe siècles. Rennes: Presses Universitaires, 2013.

STOCKHAUSEN, Karlheinz. Musik im Raum. In: STOCKHAUSEN, Karlheinz. Texte zur elektronischen und instrumentalen Musik. Colônia: DuMont, 1988 [1958]. p. 152-175.

TORCHIA, Rayan; LIPPE, Cort. Techniques for multi-channel real-time spatial distribution using frequency-domain processing. In: CONFERENCE ON NEW INTERFACES FOR MUSICAL EXPRESSION, 4., 2004, Hamamatsu. Proceedings [...]. Hamamatsu: Shizuoka University of Art and Culture, 2004. p. 116-119.

WAKEFIELD, Garry. Third-Order Ambisonics Extensions for Max/MSP with Musical Applications. In: INTERNATIONAL COMPUTER MUSIC CONFERENCE, 32., 2006, New Orleans. Proceedings [...]. San Francisco: International Computer Music Association, 2006. p. 123-126.

XENAKIS, Iannis. La voie de la recherche et de la question. In: XENAKIS, Iannis. Kéleütha Écrits. Paris: L'Arche, 1994 [1965]. p. 67-87. 
XENAKIS, Iannis. Musiques formelles. La Revue Musicale. Paris: Richard Masse, 1962.

XENAKIS, Iannis. Vers un métamusique. In: XENAKIS, Iannis. Musique architecture. 2. ed. Tournai: Casterman, 1976 [1967]. p. 38-70. 